\title{
Photocatalytic oxidation of dihydropyrimidinones using titanium dioxide suspension
}

\author{
Masoud Nasr-Esfahani,* Morteza Montazerozohori, and Karim Abdi \\ Department of Chemistry, Yasouj University, Yasouj 75918-74831, Iran \\ E-mail:
}

\begin{abstract}
Photocatalytic oxidation has been used for the oxidation of some ethyl 3,4-dihydropyrimidin2(1H)-one-5-carboxylates to their corresponding ethyl pyrimidin-2(1H)-one-5-carboxylates using a $\mathrm{TiO}_{2} / \mathrm{O}_{2}$ system under $\mathrm{UV}$ irradiation by a $400 \mathrm{~W}$ high pressure mercury lamp in acetonitrile. The results revealed that the order of photocatalytic activity for photooxidation was $\mathrm{TiO}_{2}$ (anatase) $>\mathrm{TiO}_{2}$ (rutile). The effects of some other physicochemical parameters such as amount of photocatalyst, $\mathrm{pH}$, solvent and time of irradiation were studied. The pyrimidinones were attained from the related dihydropyrimidinones after $2-4.5 \mathrm{~h}$. The results showed the photo stability of this type of compound.
\end{abstract}

Keywords: Titanium dioxide, photocatalytic, photooxidation, dihydropyrimidinone

\section{Introduction}

3,4-Dihydropyrimidin-2(1H)-ones (DHPMs) belong to an important class of heterocyclic compounds that have attracted interest due to their pharmacological and biological properties, such as antihypertensive, calcium channel blocking, alpha-1a-antagonism, neuropeptide Y(NPY) antagonism, antitumor, antibacterial, and antiinflammatory activities. ${ }^{1-6}$

Oxidation of DHPMs to pyrimidine-2(1H)-ones is relevant to MKC-442, a HEPT(1-[(2hydroxyethoxy)methyl]-6-(phenylthio)thymine) analogue which is in clinical trials, and similar compounds are also expected to inhibit the HIV virus. ${ }^{7}$ Several nucleosides containing 5substituted pyrimidine moiety have been shown to inhibit the growth of murine mammary carcinoma virus. ${ }^{8}$ Pyrimidine-cores with extended $\pi$-systems have interesting fluorescent properties and similar compounds are useful in the development of advanced electronic and photonic materials. ${ }^{9}$ Furthermore, it is of interest to synthesize structurally diverse pyrimidines by the oxidation of DHPMs. ${ }^{10}$ 
In contrast to the easy oxidation of typical Hantzsch dihydropyridines methods, ${ }^{11-13}$ the dehydrogenation of 3,4-dihydropyrimidin-2(1H)-ones is nontrivial. ${ }^{14,15}$ Oxidants such as $\mathrm{HNO}_{3},{ }^{16} \mathrm{PCC},{ }^{17}$ chloranil, ${ }^{17} \mathrm{KMnO}_{4} /$ clay, ${ }^{17} \mathrm{DDQ},{ }^{18} \mathrm{Co}\left(\mathrm{NO}_{3}\right)_{2}-6 \mathrm{H}_{2} \mathrm{O} / \mathrm{K}_{2} \mathrm{~S}_{2} \mathrm{O}_{8},{ }^{19}$ electrochemical oxidation $^{20}$ and $\mathrm{Pd} / \mathrm{C}^{21}$ as well as sono-thermal oxidation ${ }^{22}$ have been examined. None of these oxidations are efficient, some use excessively corrosive or harmful reagents, strong reaction conditions, or present difficulties in product isolation, and/or mostly low yields. Therefore, an alternative procedure is needed.

The potential of heterogeneous photocatalysis in chemistry is now a well-established procedure. $^{23}$ The strong oxidizing power of the photogenerated holes of semiconductors (large band gap material), the chemical inertness and resistance to both photocorrosion and decomposition reactions, which plague other band gap materials (e.g., Si, GaAs, GaP, Inp, CdS, etc.), low cost and wide availability in addition to the nontioxicity of $\mathrm{TiO}_{2}$ (anatase and rutile) and zinc oxide have made them superior photocatalysts. ${ }^{24}$ Several articles and reviews have been written on the use of semiconductor oxides as photocatalysts. ${ }^{23-30}$

With illumination of a semiconductor photocatalyst such as $\mathrm{TiO}_{2}$ by photons whose energy is equal to or higher than their band-gap energy (for anatase, $\mathrm{Eg}=3.23 \mathrm{eV}$ ), absorption of these photons occurs and the bulk of electron-hole pairs generate. These electron-hole pairs dissociate into free photoelectrons in the conduction band $\mathrm{e}_{\mathrm{CB}}^{-}$and photoholes in the valence band $\mathrm{hP}^{+} \mathrm{VB}$ (equation 1).

$$
\mathrm{TiO}_{2} \stackrel{\mathrm{hu}}{\longrightarrow} \mathrm{TiO}_{2} *\left(\mathrm{e}_{\mathrm{CB}}^{-} \ldots \mathrm{h}^{+}{ }_{\mathrm{VB}}\right)
$$

Some of the photoelectrons and photoholes can reach the surface of the photocatalyst and then an electron transfer proceeds towards adsorbed acceptor molecules and positive photoholes are transferred to adsorbed donor molecules. The photohole transfer corresponds to the cession of an electron by donor molecules to the photocatalyst. A chemical acceptor species can be photocatalytically reduced by $\mathrm{e}_{\mathrm{CB}}$ only if the conduction band potential of the photocatalyst is more negative than the redox potential of the acceptor species. In the same way, a chemical donor species can be photocatalytically oxidized by $\mathrm{hB}_{\mathrm{VB}}$ only if the valence band potential of the photocatalyst is more positive than the redox potential of the donor species. Both reactions should occur simultaneously because electroneutrality has to be maintained. ${ }^{31,32}$

In continuation of our previous studies on photochemical reactions, ${ }^{33-37}$ we report here the photocatalytic oxidation of DHPMs. To the best of our knowledge this is the first report of the oxidation of 3,4-dihydropyrimidin-2(1H)-ones using photocatalytic system. 


\section{Results and Discussion}

Our investigation showed us that UV irradiation is nesessary for the effective progress of the oxidation reactions and, without the selected oxidant and oxygen, oxidation did not occur. With this preliminary result, the optimization of important operational parameters was performed in the photooxidation reaction of 3,4-dihydropyrimidin-2(1H)-ones (Scheme 1).<smiles>[R]C1NC(=O)NC(C)=C1C(=O)OCC</smiles>

1

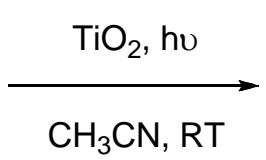

$\mathrm{CH}_{3} \mathrm{CN}, \mathrm{RT}$<smiles>[R]c1nc(=O)[nH]c(C)c1C(=O)OC</smiles>

2

\section{Scheme 1}

\section{The type of photocatalyst}

$\mathrm{TiO}_{2}$ (anatase or rutile) (40 mg) was used for the photocatalytic conversion of $1 \mathrm{mmol}$ of 5ethoxycarbonyl-6-methyl-4-phenyl-3,4-dihydropyrimidin-2(1H)-one or 5-ethoxycarbonyl-6methyl-4-(4-methoxyphenyl)-3,4-dihydropyrimidin-2(1H)-one in acetonitrile with oxygen bubbling, under irradiation. The time required for completion of the oxidation was used to compare the photocatalytic activity of semiconductor oxides. As shown in Table 1, titanium dioxide (anatase) $>$ titanium dioxide (rutile) in progressing the oxidation reaction. Perhaps, the higher oxygen uptake quantum yields and slower recombination of photogenerated electron/hole couples are responsible for the better photocatalytic activity of $\mathrm{TiO}_{2}$ anatase with respect to $\mathrm{TiO}_{2}$ rutile.

Table 1. The effect of photocatalyst type on the photocatalytic oxidation of DHPMs

\begin{tabular}{|c|c|c|c|c|c|}
\hline \multirow{3}{*}{ Entry } & \multirow{3}{*}{$\mathrm{R}$} & \multicolumn{4}{|c|}{ Type of catalyst } \\
\hline & & \multicolumn{2}{|c|}{ Anatase } & \multicolumn{2}{|c|}{ Rutile } \\
\hline & & Time (h) & Yields (\%) & Time (h) & Yields (\%) \\
\hline 1 & $\mathrm{C}_{6} \mathrm{H}_{5}$ & 3 & 90 & 5 & 50 \\
\hline 2 & 4- $\mathrm{CH}_{3} \mathrm{OC}_{6} \mathrm{H}_{4}$ & 3 & 80 & 6 & 60 \\
\hline
\end{tabular}

${ }^{\mathrm{a}}$ Isolated yields

The amount of photocatalyst

Using the better photocatalyst, the optimum amount of it required for photocatalytic oxidation was investigated. Thus, oxidations were run using various amounts of $\mathrm{TiO}_{2}$. As shown in Table 2 , oxidation times were decreased by increasing the photocatalyst quantity, then reached the 
lowest time of completion and finally remained constant at a value of $40 \mathrm{mg}$. It is interesting to note that this phenomenon has been observed previously in other photocatalytic reactions. ${ }^{38-41}$ This can be rationalized in terms of availability of active sites on the $\mathrm{TiO}_{2}$ surface and the poor penetration of photoactivating light into the suspension. The availability of active sites increases with the suspension of photocatalyst loading, but the light penetration and hence the photoactivated volume of the suspension shrinks. Moreover, the increase in the time of oxidation at higher photocatalyst loading may be due to deactivation of activated molecules by collision with ground state molecules. Shielding by $\mathrm{TiO}_{2}$ may also take place (equation 2).

$$
\mathrm{TiO}_{2}{ }^{*}+\mathrm{TiO}_{2} \rightarrow \mathrm{TiO}_{2}+\mathrm{TiO}_{2}{ }^{*}
$$

Where $\mathrm{TiO}_{2}{ }^{*}$ is the $\mathrm{TiO}_{2}$ with active species adsorbed on its surface and $\mathrm{TiO}_{2}$ is the deactivated form.

Table 2. The effects of photocatalyst amounts of Titanium dioxide on the oxidation of typical 3,4dihydropyrimidin- $2(1 H)$-one ${ }^{\mathrm{a}}$

\begin{tabular}{cccc}
\hline Entry & Amount of $\mathrm{TiO}_{2}(\mathrm{mg})$ & Time $(\mathrm{h})$ & Yields $(\%)^{\mathrm{b}}$ \\
\hline 1 & 10 & 6 & 85 \\
2 & 20 & 4.5 & 88 \\
3 & 40 & 3 & 90 \\
4 & 60 & 4 & 86 \\
5 & 80 & 5.5 & 84 \\
\hline
\end{tabular}

${ }^{\mathrm{a}} \mathrm{Tiio}_{2}$ (anatase) as photocatalyst and 5-ethoxycarbonyl-6-methyl-4-phenyl-3,4dihydropyrimidin-2(1H)-one as typical DHPMs were used.

${ }^{\mathrm{b}}$ Isolated yields.

\section{Effect of pH}

The potentials of both valence and conduction bands of $\mathrm{TiO}_{2}$ follow a pH dependence, according to equations 3 and 4, that show decreasing $59 \mathrm{mV}$ per $\mathrm{pH}$ unit and consequently, the ability of electrons and holes to participate in redox processes is determined by the $\mathrm{pH}$ of the medium. ${ }^{42}$ These equations are associated with $\mathrm{TiO}_{2}$ in anatase form at $25^{\circ} \mathrm{C}$.

$$
\begin{aligned}
& \mathrm{E}_{\mathrm{CB}}=-0.05-0.059 \mathrm{pH} \\
& \mathrm{E}_{\mathrm{VB}}=3.15-0.059 \mathrm{pH}
\end{aligned}
$$

The effects of varying of $\mathrm{pH}$ from 3-11 are summarized in Table 3. From the table we see that $\mathrm{pH} 7$ was optimum in the presence of $\mathrm{TiO}_{2}$ (anatase). It seems that, since $\mathrm{TiO}_{2}$ usually has an isoelectric point of charge at a $\mathrm{pH}$ about $\sim 7$, its surface will gain a positive charge at $\mathrm{pHs}$ lower than $\sim 7$ via protonation (equation 5) and a negative charge when the material is suspended in a 
solution with $\mathrm{pHs}$ higher than $\sim 7$ via deprotonation (equation 6 ), respectively. At $\mathrm{pHs}$ lower than $\sim 7$, both the titled compounds and $\mathrm{TiO}_{2}$ surface are present mostly in positively charged and protonated form and therefore repel each other. At $\mathrm{pH} \mathrm{7,} \mathrm{both} \mathrm{the} \mathrm{DHPMs} \mathrm{and} \mathrm{photocatalyst}$ surface are mostly in neutral and in an un-protonated form and therefore the substrate molecules are more readily adsorbed on to the photocatalyst surface and the DHPMs oxidation reaction is favored. $^{43}$

$$
\begin{aligned}
& \mathrm{TiOH}+\mathrm{H}^{+} \leftrightarrows \mathrm{TiOH}_{2}^{+} \\
& \mathrm{TiOH}+\mathrm{OH}^{-} \leftrightarrows \mathrm{TiO}^{-}+\mathrm{H}_{2} \mathrm{O}
\end{aligned}
$$

Table 3. Effect of $\mathrm{pH}$ on the photocatalytic oxidation of DHPMs ${ }^{\mathrm{a}}$

\begin{tabular}{cccc}
\hline Entry & $\mathrm{pH}$ & Time $(\mathrm{h})$ & ${\text { Yields }(\%)^{\mathrm{c}}}^{-}$ \\
\hline 1 & 3 & 6 & 85 \\
2 & 5 & 4.5 & 87 \\
3 & 7 & 3 & 90 \\
4 & 9 & 4 & 86 \\
5 & 11 & 7 & 88 \\
\hline
\end{tabular}

${ }^{\mathrm{a}} \mathrm{TiO}_{2}$ (anatase) as photocatalyst and 5-ethoxycarbonyl-6-methyl-4-phenyl3,4-dihydropyrimidin-2(1H)-one as typical DHPMs were used.

${ }^{\mathrm{b}}$ The typical DHPMs were converted to the corresponding ethyl pyrimidin2(1H)-one-5-carboxylate.

' Isolated yields.

\section{Photocatalytic oxidation of dihydropyrimidinones}

In the optimum conditions, the photocatalytic reactions (Scheme 1) proceed efficiently in high yields. The results are summarized in Table 4. DHPMs with electron withdrawing substituents take longer reaction times than those with electron donor substituents. 
Table 4. Photocatalytic oxidation of 3,4-Dihydropyrimidin-2(1H)ones with $\mathrm{TiO}_{2} / \mathrm{O}_{2}$ system

\begin{tabular}{|c|c|c|c|c|c|c|}
\hline \multirow[b]{2}{*}{ Entry } & \multirow[b]{2}{*}{ Products $^{\mathrm{a}}$} & \multicolumn{2}{|c|}{$\mathrm{TiO}_{2}$ (anatase) } & \multicolumn{2}{|c|}{$\mathrm{TiO}_{2}$ (rotile) } & \multirow[b]{2}{*}{$m p{ }^{\circ} \mathrm{C}$} \\
\hline & & Time $(\mathrm{h})$ & Yields $(\%)^{\mathrm{b}}$ & Time $(\mathrm{h})$ & Yields (\%) & \\
\hline 1 & & 3 & 90 & 5 & 50 & $133-134^{22}$ \\
\hline 2 & & 2.5 & 95 & 5 & 57 & $180-182$ \\
\hline 3 & & 3 & 85 & 6 & 50 & $151-153^{22}$ \\
\hline 4 & & 2 & 96 & 4.5 & 55 & $185-186$ \\
\hline 5 & & 4.5 & 80 & 8 & 45 & $190-192^{44}$ \\
\hline 6 & & 4 & 85 & 6 & 35 & $152-154^{22}$ \\
\hline 7 & & 2 & 95 & 4 & 53 & $136-138^{22}$ \\
\hline
\end{tabular}


Table 4. Continued

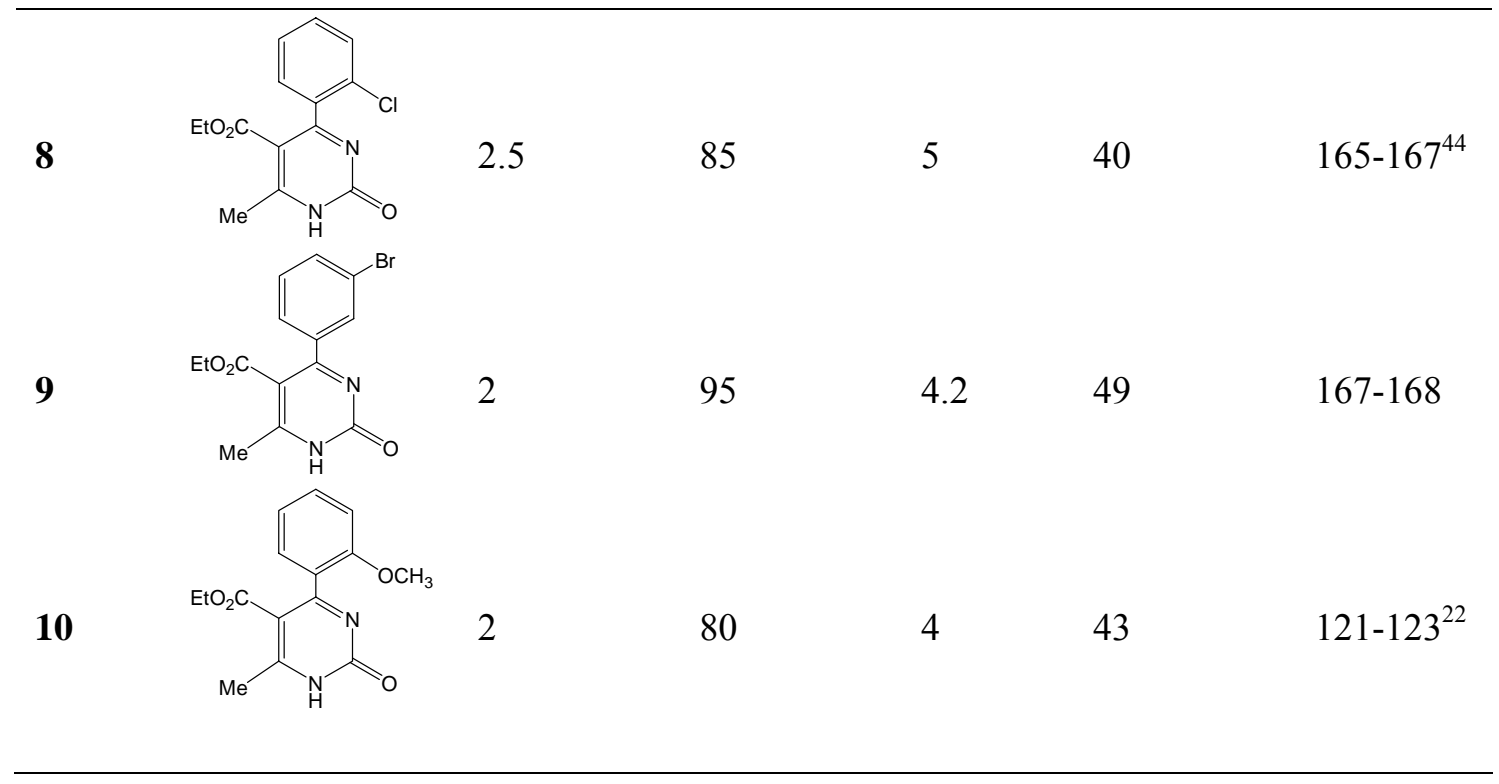

${ }^{\text {a }}$ Characterized by spectral analysis and comparison with authentic samples. ${ }^{22,44}$

${ }^{\mathrm{b}}$ Yields refer to isolated and purified products.

\section{Comparative results}

To demonstrate the potential of our new approach, the presently obtained experimental results and the data acquired with the other methodologies are compared in Table 5. The yield/time ratios of the present method are better or comparable with others.

Table 5. Comparison of some our results with those reported in the litrature ${ }^{\mathrm{a}}$

\begin{tabular}{cccc}
\hline Entry $^{\mathrm{b}}$ & $\mathrm{A}^{\mathrm{c}}$ & $\mathrm{B}$ & $\mathrm{C}$ \\
\hline $\mathbf{1}$ & $90 / 3$ & $83 / 1$ & $92 / 11$ \\
$\mathbf{2}$ & $95 / 2.5$ & - & - \\
$\mathbf{3}$ & $85 / 3$ & $81 / 1$ & $92 / 7$ \\
$\mathbf{5}$ & $80 / 4.5$ & $80 / 1$ & - \\
$\mathbf{6}$ & $85 / 4$ & - & $90 / 27$ \\
$\mathbf{7}$ & $95 / 2$ & - & $90 / 7$ \\
$\mathbf{8}$ & $85 / 2.5$ & $85 / 1$ & $90 / 5$ \\
\hline
\end{tabular}

${ }^{\mathrm{a}}$ Values refer to yield(\%)/time(h for A, B, C and min for D) ratios;

${ }^{\mathrm{b}}$ The entries refer to those in Table 4;

${ }^{\mathrm{c}} \mathrm{A}$ : Our method; B: $\mathrm{CAN}$ (3 eq.), $\mathrm{NaHCO}_{3}$ (5 eq.), aq. Acetone, $\operatorname{argon}$ atm., $-5{ }^{\circ} \mathrm{C} ;{ }^{44} \mathrm{C}: \mathrm{K}_{2} \mathrm{~S}_{2} \mathrm{O}_{8}$, aq. $\mathrm{CH}_{3} \mathrm{CN}, 70{ }^{\circ} \mathrm{C}$, Ultrasonic. ${ }^{22}$ 


\section{Conclusions}

The reported work demonstrates that using the $\mathrm{TiO}_{2} / \mathrm{O}_{2}$ photocatalytic system for dehydrogenation of 3,4-dihydropyrimidin-2 $(1 H)$-ones enhances the reaction rate compared to thermal oxidation. The results also show that $\mathrm{TiO}_{2}$ in anatase form is more effective than its rutile form in the oxidation. Easy reaction progress, moderate reaction times and good to excellent yields are some advantages of this oxidative method.

\section{Experimental Section}

General Procedures. Chemicals were purchased from Merck, Fluka and Aldrich chemical companies. The commercially available $\mathrm{TiO}_{2}$ powders were anatase in crystalline form with a surface area about $50 \mathrm{~m}^{2} / \mathrm{g}$ and primary particle size of $30 \mathrm{~nm}$ and rutile with approximate 0.2 micron in size and surface area of about $14.747 \mathrm{~m}^{2} / \mathrm{g}$. 3,4-Dihydropyrimidin-2(1H)-ones were prepared according to the reported procedures. ${ }^{45}$ Reactions were monitored by TLC. The products were isolated and identified by comparison of their physical and spectral data with authentic samples. IR spectra were recorded on FT-IR 680-Jasco-instrument model. ${ }^{1} \mathrm{H}$ NMR data were obtained on $300 \mathrm{MHz}$ DPX-Brucker model.

\section{General procedure for the photocatalytic oxidation of 3,4-dihydropyrimidin-2(1H)-ones} Titanium dioxide ( $40 \mathrm{mg}, \mathrm{TiO}_{2}$ ) was added to a solution containing a DHPM (1 mmol) in $20 \mathrm{~mL}$ acetonitrile through which oxygen was bubbling. The mixture was stirred at room temperature with irradiation by UV light ( $400 \mathrm{~W}$ high pressure mercury lamp) for the appropriate time (2$6 \mathrm{~h})$. After completion of the reaction, as monitored by TLC $\left(\mathrm{CCl}_{4}\right.$ : EtOAc), the titanium dioxide was separated by centrifugation. Evaporation of the solvent followed by chromatography on a silica-gel plate afforded the pure products.

Ethyl 6-methyl-4-(4-chlorophenyl)pyrimidin-2(1H)-one-5-carboxylate (2). Pale yellow solid; mp $180-182{ }^{\circ} \mathrm{C}$. IR (KBr): $3255,1705,1642,1410$ and $1250 \mathrm{~cm}^{-1} .{ }^{1} \mathrm{H}$ NMR (DMSO-d $\mathrm{d}_{6}$ ): $\delta=$ $1.15(\mathrm{t}, 3 \mathrm{H}, J=7.2 \mathrm{~Hz}), 2.52$ (s, 3H), $4.03(\mathrm{q}, 2 \mathrm{H}, J=7.2 \mathrm{~Hz}), 7.24-7.41(\mathrm{~m}, 4 \mathrm{H}), 10.73(\mathrm{~s}, 1 \mathrm{H})$ ppm. Anal. Calcd. for $\mathrm{C}_{14} \mathrm{H}_{13} \mathrm{ClN}_{2} \mathrm{O}_{3}$ : C 57.44, $\mathrm{H} 4.48, \mathrm{~N} 9.57 \%$ found: $\mathrm{C} 57.3, \mathrm{H} 4.4, \mathrm{~N} 9.4 \%$

Ethyl 6-methyl-4-(2,6-dichlorophenyl)pyrimidin-2(1H)-one-5-carboxylate (4). Pale yellow solid; mp 185-186 ${ }^{\circ} \mathrm{C}$. IR (KBr): 3235, 2930, 1700, 1670, $14301200 \mathrm{~cm}^{-1} .{ }^{1} \mathrm{H}$ NMR (DMSO$\left.\mathrm{d}_{6}\right): \delta=0.85(\mathrm{t}, 3 \mathrm{H}, J=7.3 \mathrm{~Hz}), 2.50(\mathrm{~s}, 3 \mathrm{H}), 3.94(\mathrm{q}, 2 \mathrm{H}, J=7.3 \mathrm{~Hz}), 7.17-7-29(\mathrm{~m}, 3 \mathrm{H}), 12.73$ (s, $1 \mathrm{H})$ ppm. Anal. Calcd. for $\mathrm{C}_{14} \mathrm{H}_{12} \mathrm{Cl}_{2} \mathrm{~N}_{2} \mathrm{O}_{3}$ : C 51.40, H 3.70, N 8.56\% found: C 51.5, H 3.8, N $8.7 \%$

Ethyl 6-methyl-4-(3-bromophenyl)pyrimidin-2(1H)-one-5-carboxylate (9). Pale yellow solid; mp 167-168 ${ }^{\circ} \mathrm{C}$. IR (KBr): 3230, 2900, 1700, 1650, 1470 and $1226 \mathrm{~cm}^{-1} .{ }^{1} \mathrm{H}$ NMR (DMSO-d 6 ): $\delta=0.92(\mathrm{t}, 3 \mathrm{H}, J=7.2 \mathrm{~Hz}), 2.41(\mathrm{~s}, 3 \mathrm{H}), 3.88(\mathrm{q}, 2 \mathrm{H}, J=7.2 \mathrm{~Hz}), 7.20-7-45(\mathrm{~m}, 3 \mathrm{H}), 9.25(\mathrm{~s}$, 
1H) ppm. Anal. Calcd. for $\mathrm{C}_{14} \mathrm{H}_{13} \mathrm{BrN}_{2} \mathrm{O}_{3}$ : C 49.87, $\mathrm{H} 3.89, \mathrm{~N} 8.31 \%$ found: $\mathrm{C} 50.0, \mathrm{H} \mathrm{3.8,} \mathrm{N}$ $8.4 \%$

\section{Acknowledgements}

The partial support of this work by Yasouj University is acknowledged.

\section{References}

1. Atwal, K. S.; Rovnyak, G. C.; O’Reilly, B. C.; Schwartz, J. J. Org. Chem. 1989, 54, 5898.

2. Rovnyak, G. C.; Kimball, S. D.; Beyer, B.; Cucinotta, G.; Dimarco, J. D.; Gougoutas, J.; Hedberg, A.; Malley, M.; McCarthy, J. P.; Zhang, R.; Moreland, S. J. Med. Chem. 1995, 38, 119.

3. Kappe, C. O.; Fabian, W. M. F. ; Semones, M. A. Tetrahedron 1997, 53, 2803.

4. Hu, E. H.; Sidler, D. R.; Dolling, U. H. J. Org. Chem. 1998, 63, 3454.

5. Atwal, K. S.; Swanson, B. N.; Unger, S. E.; Floyd, D. M.; Moreland, S.; Hedberg, A.; O’Reilly, B. C. J. Med. Chem. 1991, 34, 806.

6. Grover, G. J.; Dzwonczyk, S.; McMullen, D. M.; Normandin, D. E.; Parham, C. S.; Sleph, P. G.; Moreland, S. J. Cardiovasc. Pharmacol. 1995, 26, 289.

7. Rizzo, R. C.; Tirado-Rives, J.; Jorgensen, W. L. J. Med. Chem. 2001, 44, 145.

8. Chen, C.; Wilcoxen, K. M.; Huang, C. Q.; Xie, Y. -F., McCarthy, J. R.; Webb, T. R.; Zhu, Y. -F.; Saunders, J.; Liu, X. -J.; Chen, T. -K.; Bozigian, H.; Grigoriadis, D. E. J. Med. Chem. 2004, 47, 4787.

9. Itami, K.; Yamazaki, D.; Yoshida, J. J. Am. Chem. Soc. 2004, 126, 15396.

10. Kang, F. -A.; Kodah, J.; Guan, O.; Li, X.; Murray, W. V. J. Org. Chem. 2005, 70, 1957.

11. Moghadam, M.; Nasr-Esfahani, M.; Tangestaninejad, S.; Mirkhani, V.; Zolfigol, M. A. Can. J. Chem. 2006, 84,1.

12. Montazerozohori, M.; Karami, B.; Nasr-Esfahani, M.; Musavi, S. A. Heterocycl. Commun. 2007, 13, 289.

13. Nasr-Esfahani, M.; Moghadam, M.; Valipour, G. J. Iran. Chem. Soc. 2008, 5, 244.

14. Kappe, C. O. Tetrahedron 1993, 49, 6937.

15. Vanden Eynde, J. J.; Audiart, N.; Canonne, V.; Michel, S.; Van Haverbeke, Y.; Kappe, C. O. Heterocycles 1997, 45, 1967.

16. Puchala, A.; Belaj, F.; Bergman, J.; Kappe, C. O. J. Heterocycl. Chem. 2001, 38, 1345.

17. Vanden Eynde, J. J.; Audiart, N.; Canonne, V.; Michel, S.; Van Haverbeke, Y.; Kappe, C. O. Heterocycles 1997, 45, 1967.

18. Watanabe, M.; Koike, H.; Ishiba, T.; Okada, T.; Seo, S.; Hirai, K. Bioorg. Med. Chem. 1997, $5,437$. 
19. Shanmugam, P.; Perumal, P. T. Tetrahedron 2007, 63, 666.

20. Kadysh, V.; Stradins, J.; Khanina, H.; Duburs, G. Electrochim. Acta 1989, 34, 899.

21. Kappe, C. O.; Roschger, P. J. Heterocycl. Chem. 1989, 26, 55.

22. Memarian, H. R.; Farhadi, A. Ultrason. Sonochem. 2008, 15, 1015.

23. Fox, M. A.; Dulay, M. T. Chem. Rev. 1993, 93, 341.

24.Fox, M. A. in Photocatalysis- Fundamentals and Applications; Wiley-Interscience: New York, 1990, p. 421.

25. Bard, A. J. J. Phys. Chem. 1982, 86, 172.

26. Fox, M. A. in Advances in photochemistry, Volman, Hammond, Gollnick (Ed.), Vol 13, Wiley \& Sons Inc., 1986.

27. Serpone, N. J. Photochem. Photobiol. A; Chem. 1997, 104,1.

28. Fujishima, A. XI International Conference on Photochemical Conversion and Strong of Solar Energy (IPS-11), V, Krishnan, Ed., July 28-August 2, 1996, Bangalore, India,1996, p 11.

29. Linsebigler, A. L.; Lu, G. Q.; Yates, J. T. Chem. Rev. 1995, 95, 735.

30. Hoffmann, M. R.; Martin, S. T.; Choi,W. Y.; Bahnemann, D. W. Chem. Rev. 1995, 95, 69.

31. Herrmann, J. -M. Top. Catal. 2005, 34, 49.

32. Litter, M. I. Appl. Catal. B: Environ. 1999, 23, 89.

33. Memarian, H. R.; Nasr-Esfahani, M.; Döpp, D. New J. Chem. 2001, 25, 476.

34. Memarian, H. R.; Nasr-Esfahani, M.; Döpp, D. New J. Chem. 2001, 25, 1605.

35. Memarian, H. R.; Nasr-Esfahani, M.; Böese, R., Döpp, D. Liebigs Ann. 1997, 1023.

36. Habibi, M. H.; Isfahani, A. Z.; Mohammadkhani, A.; Montazerozohori, M. Monatsh. Chem. 2004, 135, 1121.

37. Habibi, M. H.; Tangestaninejad, S.; Mohammadpoor-Baltork, I.; Montazerozohori, M. Phosphorus Sulfur Silicon Relat. Elem. 2004, 179, 597.

38. Sakthivel, S.; Neppolian, B.; Shankar, M. V.; Arabindoo, B.; Palanichamy, M.; Murugesan, V. Sol. Energ. Mat. Sol. C. 2003, 77, 65.

39. Ohno, T., Sarukawa, K.; Matsumura, M. J. Phys.Chem. B 2001, 105, 2417.

40. Davis, R. J.; Gainer, J. L.; O’Neal, G.; Wu, I. W. Water Environ. Res. 1994, 66, 50.

41. Saien, J.; Ardjmand, R. R.; Iloukhani, H. Phys. Chem. Liq. 2003, 41, 519.

42. Chen, D.; Ray, A. K. Chem. Eng. Sci. 2001, 56, 1561.

43. Konstantinou, I. K.; Albanis, T. A. Appl. Catal. B: Environ. 2004, 49, 1.

44. Shanmugam, P.; Perumal, P. T. Tetrahedron 2006, 62, 9726.

45. Nasr-Esfahani, M.; Karami, B.; Montazerozohori, M.; Abdi, K. J. Heterocycl. Chem. 2008, 45, 1183. 